\title{
Association between viscoelastic tests- guided therapy with synthetic factor concentrates and allogenic blood transfusion in liver transplantation: a before-after study
}

Raffael P. C. Zamper ${ }^{1 *}$ (D, Thiago C. Amorim², Veronica N. F. Queiroz², Jordana D. O. Lira², Luiz Guilherme V. Costa', Flavio Takaoka ${ }^{1}$, Nicole P. Juffermans ${ }^{4}$ and Ary S. Neto ${ }^{3,4}$

\begin{abstract}
Background: Perioperative bleeding and transfusion are important causes of morbidity and mortality in patients undergoing liver transplantation. The aim of this study is to assess whether viscoelastic tests-guided therapy with the use of synthetic factor concentrates impact transfusion rates of hemocomponents in adult patients undergoing liver transplantation.

Methods: This is an interventional before-after comparative study. Patients undergoing liver transplantation before the implementation of a protocol using thromboelastometry and synthetic factor concentrates were compared to patients after the implementation. Primary outcome was transfusion of any hemocomponents. Secondary outcomes included: transfusion of red blood cells (RBC), fresh frozen plasma (FFP), cryoprecipitate or platelets, clinical complications, length of stay and in-hospital mortality.

Results: A total of 183 patients were included in the control and 54 in the intervention phase. After propensity score matching, the proportion of patients receiving any transfusion of hemocomponents was lower in the intervention phase (37.0 vs 58.4\%; OR, 0.42; 95\% Cl, 0.20-0.87; $p=0.019$ ). Patients in the intervention phase received less $\mathrm{RBC}(30.2$ vs $52.5 \% ; \mathrm{OR}, 0.21 ; 95 \% \mathrm{Cl}, 0.08-0.56 ; p=0.002)$ and FFP $(5.7$ vs $27.3 \% ; \mathrm{OR}, 0.11 ; 95 \% \mathrm{Cl}, 0.03-0.43 ; p=$ 0.002). There was no difference regarding transfusion of cryoprecipitate and platelets, complications related to the procedure, hospital length of stay and mortality.
\end{abstract}

Conclusions: Use of a viscoelastic test-guided transfusion algorithm with the use of synthetic factor concentrates reduces the transfusion rates of allogenic blood in patients submitted to liver transplantation.

Trial registration: This trial was registered retrospectively on November 15th, 2018 - clinicaltrials.gov - Identifier: NCT03756948.

Keywords: Liver transplantation, Blood coagulation disorders, Blood transfusion, Hemostasis, Hemorrhage, Prothrombin complex concentrate, Fibrinogen

\footnotetext{
* Correspondence: rzamper@me.com

${ }^{1}$ Department of Transplant Anesthesia, Hospital Israelita Albert Einstein, Rua

Galeno de Almeida 107 ap 172-A, Pinheiros, SP 05410-030, Brazil

Full list of author information is available at the end of the article
}

(c) The Author(s). 2018 Open Access This article is distributed under the terms of the Creative Commons Attribution 4.0 International License (http://creativecommons.org/licenses/by/4.0/), which permits unrestricted use, distribution, and reproduction in any medium, provided you give appropriate credit to the original author(s) and the source, provide a link to the Creative Commons license, and indicate if changes were made. The Creative Commons Public Domain Dedication waiver (http://creativecommons.org/publicdomain/zero/1.0/) applies to the data made available in this article, unless otherwise stated. 


\section{Introduction}

Perioperative bleeding is one of the most important causes of morbidity and mortality in liver transplantation [1]. However, blood transfusion, used to correct hemorrhage and coagulopathy, is directly associated with an increase in infectious and respiratory complications [2, 3], longer intensive care unit (ICU) length of stay, and a higher rate of reoperations [4-6], increasing mortality among these patients [7]. In addition, transfusion of packed red blood cells (RBC) was shown to be associated with the incidence of hepatic artery thrombosis [8] and the use of cryoprecipitate, platelets and fresh frozen plasma (FFP) associated with decreased graft survival at one and five years [9]. The decision to transfuse a patient undergoing liver transplantation presents as a challenge, and more than a half of patients undergoing liver transplantation still require transfusion of some blood product components in the perioperative period [9-15].

Patients with advanced liver diseases present with changes in coagulation and hemostasis, including an elevated international normalized ratio (INR), decreased levels of fibrinogen and a decreased platelet count, and these abnormal values suggest a state of hypocoagulability [16]. However, thrombin generating capacity is normal or even increased in this group of patients when compared to healthy controls $[17,18]$, and the platelets are qualitatively capable of withstanding adequate thrombin generation when their total count is around $50-60 \times 10^{9} / 1$ [19]. Other features of a hypercoagulable profile include increased von Willebrand factor levels, high amounts of procoagulant platelet-derived microparticles and a hypofibrinolytic state [20]. At the end, hemostasis finds a new and fragile equilibrium [16] and the isolated conventional laboratory tests are inefficient to evaluate the coagulation status [21, 22].

Thromboelastography (TEG ${ }^{\odot}$, Haemoscope / Haemonetics, Niles, Ill) as a method to assess global hemostatic function through a simple blood sample was described in 1948 and has been used in liver transplantation since the 1980s [23, 24]. Rotational thromboelastometry (ROTEM ${ }^{\bullet}$ ) adopts the same principles of TEG, as a method that assess the viscoelastic property of whole blood allowing the evaluation of the initiation, formation, stability and lysis of the clot [23]. These point-of-care (POC) tests have become complementary tools to traditional static tests $[25,26]$, and recent studies have shown that coagulation assessment and viscoelastic tests-guided therapy during high risk procedures, such as cardiovascular surgery and trauma, can have a significant impact on the reduction of transfusion of blood products and also in the morbidity and mortality of the patients [27, 28].

Some studies support the use of viscoelastic tests (VET) in the management of perioperative liver transplant coagulation [29-31], adding valuable real-time information during the different stages of surgery. However, strategies based on these tests are still under development and the best triggers for blood transfusion are not completely known. Prior to 2007, patients in Brazil were transplanted in order of waiting list, regardless of disease severity, causing patients to undergo liver transplantation at very different stages of the disease [32], with subsequent lower transfusion rates during procedure [33]. The adoption of the 'Model for End-Stage Liver Disease' (MELD) as an organ allocation method in places with low offers of organs for donation has changed this practice. Although currently evidence suggest benefit of the use of VET in this group of patients, the impact of this intervention in patients undergoing liver transplantation in Brazil according to the MELD system is not known.

The aim of the present before-after study is to assess whether VET-guided therapy with the use of synthetic factor concentrates (fibrinogen concentrate [FC] and prothrombin complex concentrate [PCC]) is associated with decreased transfusion of blood product components in adult patients undergoing liver transplantation in a private hospital in Brazil using MELD as an organ allocation method.

\section{Methods}

\section{Ethics statement}

The protocol was approved by the local ethics committee of Hospital Israelita Albert Einstein (Comitê de Ética do Hospital Israelita Albert Einstein, São Paulo, Brazil). Written consent was applied to patients in the prospective group (intervention group), and was waived in the retrospective group (control group).

\section{Patients and setting}

The present study was performed in the operating room and in the ICU of a private teaching hospital. Data from adult patients undergoing liver transplantation were collected and analyzed. All patients undergoing deceased donor liver transplantation for chronic liver disease were considered for inclusion, and in our center split organs and donation after circulatory death are not used. The following exclusion criteria were considered: transplantation due to acute liver failure, age $<18$ years old, combined transplant recipients (e.g., liver and kidney) and those who require re-transplantation in less than thirty days after the first transplant.

\section{General Care for Liver Transplantation}

Patients were admitted to the operating room without receiving any pre-anesthetic medication, and were monitored with electrocardiogram, pulse oximetry and bi-spectral index (BIS). A 16-gauge venous access and a radial arterial line were acquired before anesthetic 
induction. After intubation, a central venous access was obtained in jugular vein preferably, and all patients were monitored with transesophageal echocardiography (TEE).

In a specific group of patients, a pulmonary-artery catheter was also used (presence of pulmonary hypertension, cardiomyopathy, or a MELD score above 30). The type of anesthesia (total intravenous or balanced) was left at the discretion of the anesthesiologist. During the whole period the same groups of anesthesiologists and surgeons were responsible for all the liver transplantations. All patients used elastic stockings and an intermittent pneumatic compressor in the lower limbs, and prophylactic heparin was not allowed during the hospitalization according to institutional protocol. At the end, all patients were referred to the ICU.

\section{Study protocol Study design}

A before-after study design was used. The before period (control phase) consisted of patients undergoing liver transplantation who were operated between 2007 and 2009, at least five years before the implementation of a protocol using VET and synthetic factor concentrates. We opted for patients operated during this period to avoid a bias, because before 2009 we did not have neither synthetic factor concentrates for using in these patients nor POC-VET available in our center.

The intervention phase consisted of patients undergoing liver transplantation operated during a 10-month period after this implementation (January 2015 to October 2015). Although this strategy led to a gap of at least five years between control and intervention cases, the team of surgeons and anesthesiologists remained the same, both with more than five years of experience in liver transplantation.

\section{Control phase}

In the control phase, transfusion of RBC was triggered by either a hemoglobin $(\mathrm{Hb})$ value below $7.0 \mathrm{~g} / \mathrm{dL}$ or by signs of hemodynamic instability (persistent hypotension, tachycardia, low arterial oxygen content, severe and acute bleeding with hypotension). Strategy of transfusion and choice of blood product to treat coagulopathies was performed guided by previous laboratory results of conventional coagulation tests when there was clinical evidence of coagulopathy, active bleeding and normal metabolic profile ( $\mathrm{pH}$, temperature and serum calcium). Synthetic factor concentrates were available, but we did not have institutional authorization for using them in an off-label setting, so the patients in the control phase did not receive these concentrates.

Antifibrinolytics were used prophylactically in all cases when there was no history of inflammatory diseases from the biliary tract, hepatocellular carcinoma and no previous thromboembolic event. There was no fluid administration protocol, but in our practice, we use albumin combined with crystalloids and tend to be restrictive with fluids administration, using the four chambers view on TEE to estimate if the heart is empty, hyperdynamic or dysfunctional. This evaluation associated with assessment of the mean arterial pressure (MAP) and central venous pressure (CVP) supported our decisions on fluid resuscitation.

ROTEM $^{\circ}$ was not available during this period. We performed a retrospective analysis of prospectively recorded data regarding demographic characteristics, laboratory tests, medications, surgical characteristics, strategy of fluid replacement, use of blood products (blood product components), vital signs, general complications after surgery, including thromboembolic complications (myocardial infarction, stroke, deep venous thrombosis, pulmonary thromboembolism or portal thrombosis), postoperative duration of mechanical ventilation, ICU and hospital length of stay, and mortality.

\section{Intervention phase}

During a 10-month period, the recommended procedure was to treat coagulopathies according to a strategy of transfusion based on the results of VET and to use synthetic factor concentrates instead of hemocomponents. As in the control phase, transfusion of RBC was triggered by either a $\mathrm{Hb}$ value under $7,0 \mathrm{~g} / \mathrm{L}$ or by signs of hemodynamic instability and fluid resuscitation was exactly as in the control group. Patients were followed until hospital discharge or death, whichever came first.

Coagulation treatment was indicated when there was a clinical coagulopathy with bleeding, and management was based on a POC-VET algorithm adapted from those used in cardiovascular surgeries, designed in conjunction with hematologists and experts in the area and using an earlier amplitude evaluation in the EXTEM at the fifth minute (A5 $5_{\mathrm{EX}}$ ) (Fig. 1) [34]. Antifibrinolytics were indicated when there was no history of inflammatory diseases from the biliary tract, hepatocellular carcinoma, no previous thromboembolic event, and if the $\mathrm{A} 5_{\mathrm{EX}}$ amplitude was under $15 \mathrm{~mm}$ in the ROTEM $^{\circ}$ performed in the beginning of the anesthesia.

ROTEM $^{\circ}$ was performed in the following moments: in the preoperative period within the routine laboratory exams in the ward, $15 \mathrm{~min}$ after arterial reperfusion, six hours after the end of the transplant in the ICU and at any time when the team considered necessary based on clinical aspects of the surgical field.

\section{Outcomes}

The primary outcome was a collapsed composite of need of any transfusion of blood product during surgery and 


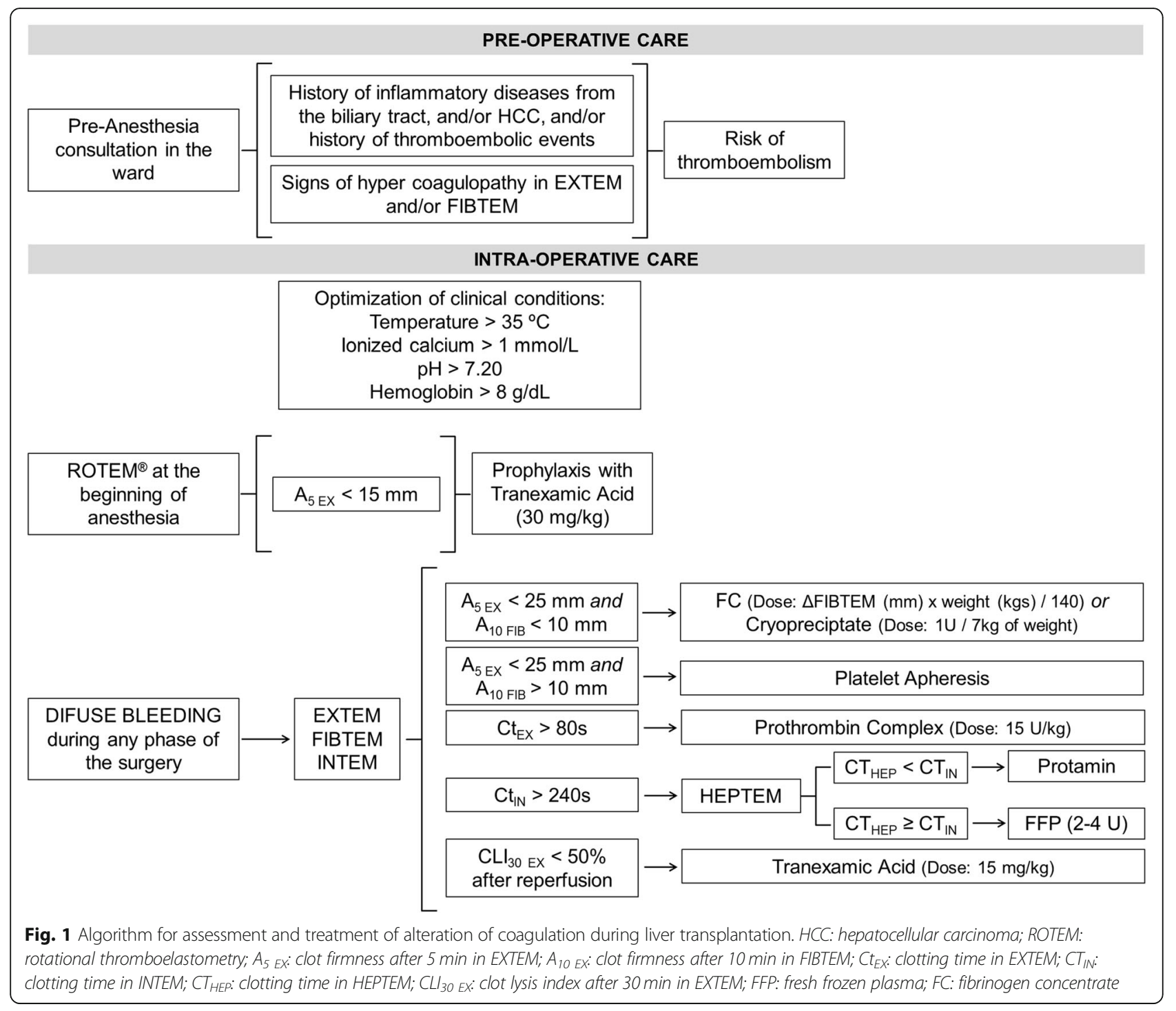

in the first $48 \mathrm{~h}$ in the postoperative, and this included the need of RBC, FFP, cryoprecipitate and/or platelets. Secondary outcomes were: 1) use of synthetic factor concentrates or antifibrinolytic; 2) clinical complications related to the procedure; 3) postoperative duration of ventilation in days; 4) ICU and hospital length of stay in days; and 5) in-hospital mortality.

\section{Statistical analysis}

The control phase has been set to liver transplantations performed between 2007 and 2009 and the intervention phase 10-months duration a priori. The control to intervention ratio was set as 3:1. The primary analysis consisted in comparing any transfusion of blood product components between the two phases by means of a chi-square test. To consider potential bias associated with the before-after design, we performed two analyses with an adjustment for demographic characteristics.
First, a multivariate analysis was performed using a logistic or a linear regression model including variables differing between the two phases in bivariate analyses and those already know as prognostic factors for transfusion in liver transplantation. Variables used for adjustment were age, MELD score, Child-Pugh classification, presence of hepatocellular carcinoma (HCC), and preoperative levels of albumin, urea, creatinine and hemoglobin. Second, a propensity score method was applied to balance covariates in the two phases and to reduce bias. Propensity scores were estimated for each patient with logistic regression using age, Child-Pugh, MELD, presence of HCC and preoperative levels of hemoglobin as co-variates. The propensity score reflects the propensity in the range of 0 to 1 to be in the intervention phase given a set of known variables and is an attempt to adjust for potential selection bias, confounding factors, and differences between groups. Patients 
with missing data were excluded from the analysis. Based on the propensity score weighted estimators for the data we constructed a propensity score-matched cohort. Matching was performed using nearest neighbor matching without replacement, with each patient from the intervention phase matched to two patients of the control phase. A caliper width of 0.1 of the standard deviation of the logit of the propensity score was used for the development of matching.

A logistic or a linear regression was performed on this matched sample. All results are presented as odds ratio $(\mathrm{OR})$ and it $95 \%$ confidence interval $(95 \% \mathrm{CI})$ for logistic regression or the $\beta$ coefficient and it $95 \%$ CI for linear regression.

Normality of the variables was tested with a Kolmogorov-Smirnoff test. Continuous parametric data were expressed as the mean (SD), and nonparametric data were expressed as median and interquartile range. Categorical data were expressed as absolute numbers and percentage. For demographic characteristics Student $t$ test was used as appropriate. All analyses were conducted with SPSS v.20 (IBM SPSS Statistics for Windows, Version 20.0. Armonk, NY: IBM Corp.), and R v.2.12.0. For all analyses two-sided $p$ values $<0.05$ were considered significant.

\section{Results}

\section{Population}

Demographic characteristics of included population are reported in Table 1 . One hundred and eighty-three patients were included in the control and fifty-four in the intervention phase. At baseline, patients in the intervention phase had lower incidence of chronic kidney disease, encephalopathy and upper digestive hemorrhage, lower preoperative levels of creatinine and urea and higher levels of albumin (Table 1). However, there were no differences between the groups when comparing MELD scores. The characteristics of the groups were more balanced after the propensity-score matching (Table 1).

\section{Postoperative and surgical characteristics}

The clamping and ischemia time was lower in the intervention phase compared to the control phase (Table 2). Intraoperatively, patients in the intervention phase received less fluid and had lower fluid balance than patients in the control phase. At the end of the surgery, patients in the intervention phase presented with a lower heart rate, CVP, and temperature and higher MAP and dose of norepinephrine compared to patients in the control phase (Table 2).

\section{Primary outcome}

The proportion of patients receiving any transfusion of blood product components was $35.2 \%$ in the intervention phase and $56.3 \%$ in the control phase $(p=0.006)$ (Table 3$)$. When considering the adjustment for potential confounders, patients in the intervention phase still had a lower risk of any transfusion of blood product components compared to those in the control phase (adjusted OR, 0.25; 95\% CI, 0.10-0.63; $p=0.003$ ) (Additional file 1: Table S1). After propensity score matching, the proportion of patients that received any transfusion of blood product components was still lower in the intervention phase (37.0 vs $58.4 \% ; p=0.018$; OR, $0.42 ; 95 \% \mathrm{CI}, 0.20-0.87 ; p=$ $0.019)$ (Table 3 and Additional file 1: Table S2).

Patients in the intervention phase received less RBC (30.2 vs $52.5 \% ; p=0.004$; adjusted OR, $0.21 ; 95 \% \mathrm{CI}$, $0.08-0.56 ; p=0.002)$ and FFP (5.7 vs $27.3 \% ; p<0.001$; adjusted OR, 0.11; 95\% CI, 0.03-0.43; $p=0.002$ ) (Table 3 and Additional file 1: Table S1). There was no difference regarding transfusion of cryoprecipitate and platelets.

\section{Secondary outcomes}

Secondary outcomes are provided in Tables 3 and 4. The use of hemoderivates was higher in the intervention phase ( 35.2 vs $0.0 \% ; p<0.001)$ and the use of antifibrinolytic agents was lower ( 14.8 vs $42.3 \%$; $p<0.001$; adjusted OR, $0.33 ; 95 \% \mathrm{CI}, 0.13-0.80 ; p=0.015$ ) (Table 3 and Additional file 1: Table S1). The results after the propensity score matching yielded the same results (Table 3 and Additional file 1: Table S2).

There was no difference regarding complications related to the procedure, duration of mechanical ventilation, ICU length of stay and hospital mortality among the two groups (Table 4 and Additional file 1: Table S3). However, hospital length of stay in survivors was lower in the intervention phase $(11.3 \pm 7.2$ vs $16.3 \pm 12.7$ days; $p=$ 0.007 ; adjusted $\beta$ coefficient, $-5.84 ; 95 \% \mathrm{CI},-9.77$ -1.91; $p=0.004$ ) (Table 4 and Additional file 1: Table S3). After propensity score matching, there was only a trend toward decreased hospital length of stay in survivors in the intervention phase $(11.6 \pm 7.5$ vs $15.1 \pm 11.4$ days; $p=$ 0.066; adjusted $\beta$ coefficient, -3.53 ; 95\% CI, $-7.22-0.17$; $p=0.061)$ (Table 4 and Additional file 1: Table S4).

\section{Discussion}

In this observational study the use of a transfusion algorithm based on ROTEM $^{\circ}$ and on the use of synthetic factor concentrates resulted in a reduction in transfusion rates of any blood product components, and in a reduction in the use of antifibrinolytic medications. No patient in the treatment group developed any major complications related to the use of the protocol.

The present study is unprecedented when introducing to liver transplantations a VET-based transfusion algorithm including the use of synthetic factor concentrates and using prospectively an earlier amplitude evaluation in the EXTEM at the fifth minute $\left(\mathrm{A} 5_{\mathrm{EX}}\right)$, and 
Table 1 Baseline characteristics of the patients

\begin{tabular}{|c|c|c|c|c|c|c|}
\hline & \multicolumn{3}{|c|}{ Unmatched Cohort $(n=237)$} & \multicolumn{3}{|c|}{ Matched Cohort $(n=135)^{b}$} \\
\hline & Intervention $(n=54)$ & Control $(n=183)$ & $p$ value $^{a}$ & Intervention $(n=46)$ & Control $(n=89)$ & $p$ value $^{a}$ \\
\hline \multicolumn{7}{|c|}{ Baseline characteristics and co-morbidities } \\
\hline Age, years & $53.0 \pm 11.1$ & $51.9 \pm 12.0$ & 0.550 & $53.0 \pm 11.8$ & $52.5 \pm 11.9$ & 0.791 \\
\hline Gender, male & 43 / 54 (79.6) & $131 / 183(71.6)$ & 0.239 & $35 / 46(76.1)$ & $71 / 89$ (79.8) & 0.620 \\
\hline Weight, kg & $77.8 \pm 15.9$ & $76.0 \pm 17.0$ & 0.483 & $76.2 \pm 16.5$ & $76.7 \pm 15.7$ & 0.867 \\
\hline Height, cm & $171.2 \pm 8.0$ & $168.3 \pm 9.9$ & 0.051 & $170.2 \pm 7.8$ & $170.1 \pm 8.6$ & 0.927 \\
\hline $\mathrm{BMI}, \mathrm{kg} / \mathrm{m}^{2}$ & $26.6 \pm 4.4$ & $26.7 \pm 5.1$ & 0.848 & $26.3 \pm 4.6$ & $26.4 \pm 4.6$ & 0.945 \\
\hline \multicolumn{7}{|l|}{ Co-morbidities } \\
\hline Chronic kidney disease & $3 / 54(5.6)$ & 34 / 183 (18.6) & 0.020 & $2 / 46(4.3)$ & $17 / 89(19.1)$ & 0.019 \\
\hline Hypertension & 14 / 54 (25.9) & $31 / 183(16.9)$ & 0.139 & $13 / 46(28.3)$ & 14 / 89 (15.7) & 0.084 \\
\hline Diabetes mellitus & $11 / 54(20.4)$ & $48 / 183(26.2)$ & 0.381 & 9 / 46 (19.6) & $28 / 89$ (31.5) & 0.141 \\
\hline Etiology of liver disease & & & 0.578 & & & 0.852 \\
\hline Budd-Chiari & $0 / 54(0.0)$ & $3 / 182(1.6)$ & & $0 / 46(0.0)$ & $1 / 89(1.1)$ & \\
\hline Alcohol & 14 / 54 (25.9) & $32 / 182(17.6)$ & & $11 / 46(23.9)$ & $22 / 89(24.7)$ & \\
\hline Hepatitis C & 23 / 54 (42.6) & 89 / $182(48.9)$ & & 19 / 46 (41.3) & 40 / $89(44.9)$ & \\
\hline Hepatitis B & $2 / 54(3.7)$ & $13 / 182(7.1)$ & & $2 / 46$ (4.3) & 8 / 89 (9.0) & \\
\hline Cryptogenic & $5 / 54(9.3)$ & $16 / 182(8.8)$ & & $4 / 46$ (8.7) & $6 / 89(6.7)$ & \\
\hline PSC & $2 / 54(3.7)$ & $6 / 182(3.3)$ & & $2 / 46$ (4.3) & $2 / 89(2.2)$ & \\
\hline Autoimmune hepatitis & $2 / 54(3.7)$ & $6 / 182(3.3)$ & & $2 / 46(4.3)$ & 3 / 89 (3.4) & \\
\hline FAP & $0 / 54(0.0)$ & $5 / 182(2.7)$ & & $0 / 46(0.0)$ & $0 / 89(0.0)$ & \\
\hline Acute Liver Failure & $0 / 54(0.0)$ & $2 / 182(1.1)$ & & $0 / 46(0.0)$ & $1 / 89(1.1)$ & \\
\hline Others & $6 / 54(11.1)$ & $10 / 182(5.5)$ & & $6 / 46(13.0)$ & $6 / 89(6.7)$ & \\
\hline \multicolumn{7}{|l|}{ Clinical status pre-transplantation } \\
\hline Use of mechanical ventilation & $2 / 54(3.7)$ & $14 / 183(7.7)$ & 0.309 & $2 / 46$ (4.3) & $6 / 89(6.7)$ & 0.576 \\
\hline Use of hemodialysis & $4 / 54(7.4)$ & $16 / 183(8.7)$ & 0.756 & $3 / 46$ (6.5) & $7 / 89$ (7.9) & 0.777 \\
\hline Previous surgery & $8 / 54(14.8)$ & 37 / $183(20.2)$ & 0.373 & $8 / 46(17.4)$ & 14 / 89 (15.7) & 0.804 \\
\hline Child-Pugh classification & & & 0.019 & & & 0.223 \\
\hline A & $13 / 54(24.1)$ & $44 / 183(24.0)$ & & $13 / 46(28.3)$ & $17 / 89(19.1)$ & \\
\hline B & $7 / 54$ (13.0) & $57 / 183(31.1)$ & & $7 / 46(15.2)$ & $24 / 89(27.0)$ & \\
\hline C & 34 / 54 (63.0) & $82 / 183(44.8)$ & & $26 / 46(56.5)$ & 48 / 89 (53.9) & \\
\hline MELD score & $22.7 \pm 8.8$ & $21.6 \pm 8.2$ & 0.418 & $21.9 \pm 9.2$ & $22.0 \pm 7.9$ & 0.954 \\
\hline Re-transplantation & $1 / 54(1.9)$ & $0 / 183(0.0)$ & 0.065 & $1 / 46(2.2)$ & $0 / 89(0.0)$ & 0.162 \\
\hline \multicolumn{7}{|l|}{ Complications } \\
\hline Encephalopathy & $1 / 54(1.9)$ & 94 / $183(51.4)$ & $<0.001$ & $1 / 46(2.2)$ & $50 / 89(56.2)$ & $<0.001$ \\
\hline Upper digestive hemorrhage & $1 / 54(1.9)$ & $67 / 183(36.6)$ & $<0.001$ & $1 / 46(2.2)$ & 37 / 89 (41.6) & $<0.001$ \\
\hline Portal vein thrombosis & $4 / 54(7.4)$ & $10 / 183(5.5)$ & 0.594 & $3 / 46(6.5)$ & 4 / 89 (4.5) & 0.614 \\
\hline Portopulmonary hypertension & $1 / 54(1.9)$ & $4 / 183(2.2)$ & 0.880 & $1 / 46(2.2)$ & $2 / 89(2.2)$ & 0.978 \\
\hline $\mathrm{HCC}$ & $23 / 54(42.6)$ & $53 / 183(29.0)$ & 0.059 & $16 / 46(34.8)$ & $28 / 89(31.5)$ & 0.696 \\
\hline Ascites & & & 0.082 & & & \\
\hline Controlled & $13 / 54(24.1)$ & $37 / 183(20.2)$ & & $12 / 46(26.1)$ & $26 / 89(29.2)$ & 0.083 \\
\hline Refractory & 14 / 54 (25.9) & 78 / 183 (42.6) & & $11 / 46(23.9)$ & 35 / 89 (39.3) & \\
\hline \multicolumn{7}{|l|}{ Medications in use } \\
\hline Furosemide & $22 / 54(40.7)$ & 53 / 183 (29.0) & 0.101 & $20 / 46(43.5)$ & 27 / 89 (30.3) & 0.128 \\
\hline Spironolactone & $27 / 54(50.0)$ & $68 / 183(37.2)$ & 0.013 & $23 / 46(50.0)$ & 37 / 89 (41.6) & 0.350 \\
\hline
\end{tabular}


Table 1 Baseline characteristics of the patients (Continued)

\begin{tabular}{|c|c|c|c|c|c|c|}
\hline & \multicolumn{3}{|c|}{ Unmatched Cohort $(n=237)$} & \multicolumn{3}{|c|}{ Matched Cohort $(n=135)^{\mathrm{b}}$} \\
\hline & Intervention $(n=54)$ & Control $(n=183)$ & $p$ value $^{a}$ & Intervention $(n=46)$ & Control $(n=89)$ & $p$ value \\
\hline Propranolol & $27 / 54(50.0)$ & $58 / 183(31.7)$ & 0.090 & $22 / 46(47.8)$ & $33 / 89(37.1)$ & 0.228 \\
\hline \multicolumn{7}{|c|}{ Pre-transplantation laboratory tests } \\
\hline INR & $1.8 \pm 0.8$ & $1.7 \pm 0.6$ & 0.113 & $1.8 \pm 0.8$ & $1.7 \pm 0.7$ & 0.532 \\
\hline Total bilirubin, mg/dL & $5.4 \pm 8.0$ & $6.2 \pm 8.1$ & 0.532 & $4.8 \pm 7.6$ & $7.2 \pm 9.6$ & 0.149 \\
\hline Albumin, $\mathrm{g} / \mathrm{dL}$ & $3.2 \pm 0.5$ & $3.0 \pm 0.6$ & 0.025 & $3.3 \pm 0.5$ & $3.0 \pm 0.6$ & 0.004 \\
\hline Hemoglobin, g/dL & $11.3 \pm 2.5$ & $11.3 \pm 2.6$ & 0.641 & $11.3 \pm 2.7$ & $10.9 \pm 2.5$ & 0.433 \\
\hline Hematocrit, \% & $32.5 \pm 7.0$ & $32.5 \pm 7.5$ & 0.954 & $32.6 \pm 7.4$ & $31.9 \pm 7.4$ & 0.633 \\
\hline Fibrinogen, mg/dL & $214.5 \pm 92.6$ & $178.3 \pm 94.5$ & 0.301 & $214.5 \pm 92.6$ & $153.7 \pm 70.2$ & 0.095 \\
\hline Platelets, $\times 1000 / \mathrm{mm}_{3}$ & $80.5 \pm 59.2$ & $74.2 \pm 55.0$ & 0.473 & $81.6 \pm 62.7$ & $67.1 \pm 48.7$ & 0.143 \\
\hline Urea, mg/dL & $36.5 \pm 15.7$ & $49.7 \pm 43.3$ & 0.030 & $35.9 \pm 14.9$ & $51.9 \pm 47.8$ & 0.028 \\
\hline Creatinine, mg/dL & $0.9 \pm 0.4$ & $1.2 \pm 0.8$ & 0.004 & $0.9 \pm 0.4$ & $1.2 \pm 0.7$ & 0.008 \\
\hline Sodium, mEq/L & $137.1 \pm 3.3$ & $137.5 \pm 5.8$ & 0.702 & $137.3 \pm 3.0$ & $137.4 \pm 6.1$ & 0.963 \\
\hline Potassium, mEq/L & $4.3 \pm 0.5$ & $4.1 \pm 0.5$ & 0.074 & $4.3 \pm 0.5$ & $4.2 \pm 0.5$ & 0.316 \\
\hline Ejection fraction of $L V, \%$ & $66.2 \pm 8.5$ & $67.0 \pm 7.3$ & 0.577 & $66.4 \pm 8.9$ & $68.3 \pm 6.6$ & 0.253 \\
\hline
\end{tabular}

associating it with the amplitude of FIBTEM at the tenth minute $\left(\mathrm{A} 10_{\mathrm{FIB}}\right)$ to support transfusion therapy with either fibrinogen or platelets.

The perioperative period of liver transplantation may result in hemostatic unbalance and massive bleeding, which often leads to a treatment based on most probable deficiencies or on laboratory results that do not reflect in vivo hemostasis. Indeed, recent studies emphasize that conventional coagulation tests have significant limitations in this scenario, such as a longer time to provide useful results, absence of correlation with the risk of intraoperative bleeding, and lack of evaluation of anticoagulant factors, fibrinolysis and platelet dysfunction [25, 35-38].

This study supports the results of previous studies that showed the effectiveness of VET in the evaluation and treatment of bleeding in high complex surgeries such as cardiovascular [39], trauma [40] and liver transplantations surgeries [29, 30, 41, 42]. The use of synthetic factor concentrates (FC and PCC) in the context of coagulopathies requiring treatment, although still an off-label treatment, has been investigated previously, and a recent study showed the safety of this therapeutic option in liver transplant patients [43]. In our study we used synthetic factor concentrates predominately, as a good alternative to replace FFP and cryoprecipitate transfusions, avoiding their intrinsic complications.

FC has been shown to be effective in the treatment of patients with hypofibrinogenemia in obstetric [44], cardiac [45], and trauma surgeries [46], improving clot function and reducing bleeding. Some authors argue that in situations where cryoprecipitate is indicated, replacement with FC offers advantages from the point of view of efficacy and safety [47]. Alternatives to the treatment of hypofibrinogenemia are limited. FFP contains insufficient amounts of fibrinogen [48] and is inefficient in the clinical situations in which it is used for fibrinogen replacement [49]. Cryoprecipitate is the therapy of choice, but offers high risks of complications such as transmission of infectious diseases, acute lung injury and immuno-mediated complications, increasing morbidity and mortality in transfused patients. Besides, high contents of von-Willebrand factor, factors VIII and XIII can potentially lead to hypercoagulation in the setting of endothelial dysfunction, contributing to the development of thromboembolic events [50-52].

It is important to note that although we did not find a difference between cryoprecipitate transfusion rates in both groups, the use of VET led to an increase in the general indication of fibrinogen replacement in the intervention group, which was done with FC. One possible explanation is that the faster evaluation of coagulation when using VET directed the treatment of coagulopathy with replacement. It is known that the majority of patients undergoing liver transplantation present intraoperative hypofibrinogenemia $[53,54]$.

FFP remains the main therapy for multifactorial coagulopathy observed in hepatic transplantation [55-57], and PCC was initially presented as an option for reversal of coumarin anticoagulant agents [58]. Although it does 
Table 2 Postoperative and surgical characteristics

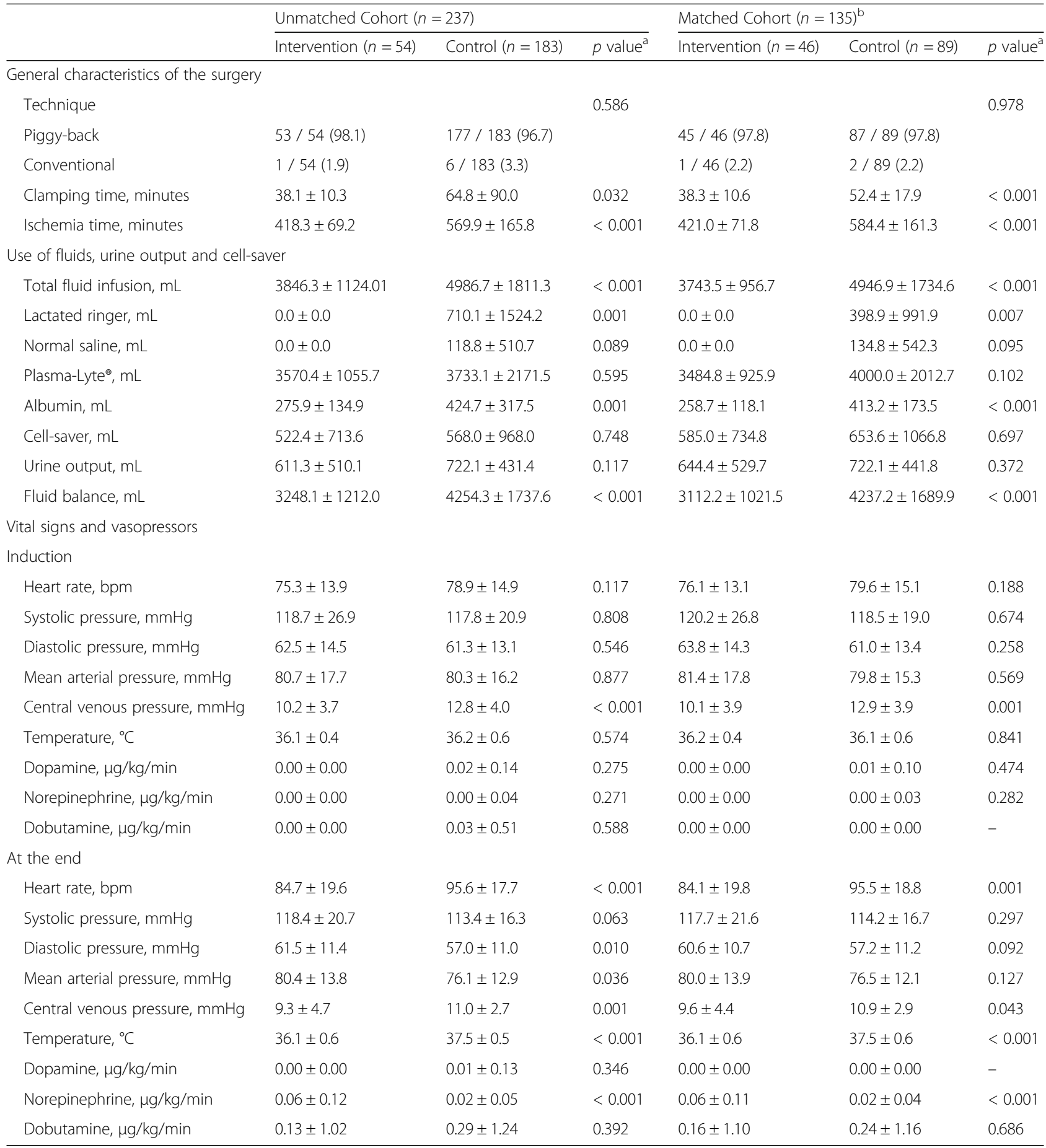

$\mathrm{mL}$ : milliliters; bpm: beats per minute

Data presented as mean \pm standard deviation or number / total (percentage)

${ }^{a}$ Comparison of differences between the two groups using the $t$ test for continuous variables and the $\mathrm{X}^{2}$ test for categorical variables

${ }^{b}$ Adjusted by age, Child, MELD, presence of HCC and pre-transplantation hemoglobin

not contain all the factors present in FFP, since it is composed of the vitamin $\mathrm{K}$ dependent factors (II, VII, IX and $\mathrm{X}$ ) and protein $\mathrm{C}$ and $\mathrm{S}$ anticoagulant factors, the PCC contains important effectors in the coagulation, and therefore, it is an alternative in cases in which the FFP is indicated [59]. It presents a low risk of thromboembolic events, and offers the advantage of lower risk of infection transmission and transfusion reactions when compared to FFP, besides low impact on the patient's blood volume, reducing the risk of volume overload and 
Table 3 Transfusion of blood products

\begin{tabular}{|c|c|c|c|c|c|c|}
\hline & \multicolumn{3}{|c|}{ Unmatched Cohort $(n=237)$} & \multicolumn{3}{|c|}{ Matched Cohort $(n=135)^{b}$} \\
\hline & Intervention $(n=54)$ & Control $(n=183)$ & $p$ value $^{a}$ & Intervention $(n=46)$ & Control $(n=89)$ & $p$ value $^{\mathrm{a}}$ \\
\hline \multicolumn{7}{|l|}{ Transfusion of hemocomponents } \\
\hline Any transfusion of hemocomponents & $19 / 54(35.2)$ & 103 / $183(56.3)$ & 0.006 & 17 / 46 (37.0) & $52 / 89(58.4)$ & 0.018 \\
\hline Red blood cells & $16 / 53(30.2)$ & $96 / 183(52.5)$ & 0.004 & $14 / 45$ (31.1) & 47 / 89 (52.8) & 0.017 \\
\hline Units transfused & $0.7 \pm 1.3$ & $1.7 \pm 2.7$ & 0.007 & $0.6 \pm 1.0$ & $1.7 \pm 2.7$ & 0.008 \\
\hline Fresh frozen plasma & $3 / 53(5.7)$ & $50 / 183(27.3)$ & $<0.001$ & $3 / 45(6.7)$ & 25 / $89(28.1)$ & 0.003 \\
\hline Units transfused & $0.2 \pm 0.8$ & $2.1 \pm 4.2$ & 0.001 & $0.2 \pm 0.9$ & $2.2 \pm 4.5$ & 0.004 \\
\hline Cryoprecipitate & $3 / 54(5.6)$ & $11 / 183(6.0)$ & 0.900 & $3 / 46$ (6.5) & $5 / 89(5.6)$ & 0.833 \\
\hline Units transfused & $0.4 \pm 2.1$ & $0.4 \pm 1.8$ & 0.876 & $0.5 \pm 2.3$ & $0.4 \pm 1.9$ & 0.938 \\
\hline Platelets & $10 / 54(18.5)$ & $31 / 183(16.9)$ & 0.787 & $10 / 46(21.7)$ & $16 / 89(18.0)$ & 0.599 \\
\hline Units transfused (random) & $0.0 \pm 0.0$ & $0.1 \pm 0.6$ & 0.443 & $0.0 \pm 0.0$ & $0.1 \pm 0.6$ & 0.474 \\
\hline Units transfused (apheresis) & $0.2 \pm 0.4$ & $0.2 \pm 0.4$ & 0.871 & $0.2 \pm 0.4$ & $0.2 \pm 0.5$ & 0.963 \\
\hline \multicolumn{7}{|l|}{ Transfusion of hemoderivatives } \\
\hline Any transfusion of hemoderivatives & 19 / 54 (35.2) & 0 / $183(0.0)$ & $<0.001$ & $17 / 46(37.0)$ & $0 / 89(0.0)$ & $<0.001$ \\
\hline Fibrinogen concentrate & $18 / 54(33.3)$ & $0 / 183(0.0)$ & $<0.001$ & $16 / 46(34.8)$ & $0 / 89(0.0)$ & $<0.001$ \\
\hline Grams transfused & $1.4 \pm 2.3$ & $0.0 \pm 0.0$ & $<0.001$ & $1.4 \pm 2.4$ & $0.0 \pm 0.0$ & $<0.001$ \\
\hline Prothrombin complex concentrate & $6 / 54(11.1)$ & $0 / 183(0.0)$ & $<0.001$ & $5 / 46(10.9)$ & $0 / 89(0.0)$ & 0.001 \\
\hline Units transfused & $222.2 \pm 711.5$ & $0.0 \pm 0.0$ & $<0.001$ & $195.6 \pm 645.3$ & $0.0 \pm 0.0$ & 0.005 \\
\hline Use of antifibrinolytic & $8 / 54(14.8)$ & 77 / $182(42.3)$ & $<0.001$ & $7 / 46(15.2)$ & 36 / 88 (40.9) & $<0.001$ \\
\hline Tranexamic acid & $8 / 54$ (14.8) & 0 / $182(0.0)$ & & 7 / 46 (15.2) & $0 / 88(0.0)$ & \\
\hline Aprotinin & $0 / 54(0.0)$ & $29 / 182(15.9)$ & & $0 / 46(0.0)$ & 15 / 88 (17.0) & \\
\hline Epsilon-aminocaproic acid & $0 / 54(0.0)$ & 48 / $182(26.4)$ & & $0 / 46(0.0)$ & 21 / 88 (23.9) & \\
\hline
\end{tabular}

Data presented as mean \pm standard deviation or number / total (percentage)

${ }^{a}$ Comparison of differences between the two groups using the $t$ test for continuous variables and the $x^{2}$ test for categorical variables

${ }^{\mathrm{b}}$ Adjusted by age, Child, MELD, presence of HCC and pre-transplantation hemoglobin

Table 4 Clinical outcomes after transplantation

\begin{tabular}{|c|c|c|c|c|c|c|}
\hline & \multicolumn{3}{|c|}{ Unmatched Cohort ( $n=237)$} & \multicolumn{3}{|c|}{ Matched Cohort $(n=135)^{b}$} \\
\hline & Intervention $(n=54)$ & Control $(n=183)$ & $p$ value $^{a}$ & Intervention $(n=46)$ & Control $(n=89)$ & $p$ value $^{2}$ \\
\hline \multicolumn{7}{|l|}{ Related to the procedure } \\
\hline 2003Any complication & $25 / 53(47.2)$ & $99 / 183(54.1)$ & 0.373 & $21 / 45(46.7)$ & 44 / 89 (49.4) & 0.761 \\
\hline Upper digestive hemorrhage & 10 / 53 (18.9) & $54 / 174(31.0)$ & 0.084 & $10 / 45(22.2)$ & $27 / 84(32.1)$ & 0.235 \\
\hline Arterial thrombosis & $1 / 53(1.9)$ & $6 / 172(3.5)$ & 0.557 & $1 / 45(2.2)$ & $2 / 82(2.4)$ & 0.938 \\
\hline \multicolumn{7}{|l|}{ General } \\
\hline Duration of mechanical ventilation & $0.5 \pm 1.1$ & $1.1 \pm 3.9$ & 0.242 & $0.5 \pm 1.2$ & $0.9 \pm 1.4$ & 0.110 \\
\hline Survivors & $0.4 \pm 1.1$ & $0.8 \pm 1.2$ & 0.052 & $0.4 \pm 1.1$ & $0.8 \pm 1.4$ & 0.094 \\
\hline ICU length of stay & $3.2 \pm 4.0$ & $4.2 \pm 6.6$ & 0.290 & $3.4 \pm 4.3$ & $3.6 \pm 4.6$ & 0.781 \\
\hline Survivors & $2.8 \pm 2.7$ & $3.6 \pm 5.3$ & 0.306 & $2.9 \pm 2.9$ & $3.5 \pm 4.6$ & 0.463 \\
\hline Hospital length of stay & $12.1 \pm 8.9$ & $17.2 \pm 15.4$ & 0.022 & $12.4 \pm 9.5$ & $16.1 \pm 16.6$ & 0.172 \\
\hline Survivors & $11.3 \pm 7.2$ & $16.3 \pm 12.7$ & 0.007 & $11.6 \pm 7.5$ & $15.1 \pm 11.4$ & 0.066 \\
\hline In-hospital mortality & $1 / 53(1.9)$ & $11 / 182(6.0)$ & 0.226 & $1 / 45$ (2.2) & $5 / 89(5.6)$ & 0.369 \\
\hline
\end{tabular}

ICU: intensive care unit

Data presented as mean \pm standard deviation or number / total (percentage)

${ }^{a}$ Comparison of differences between the two groups using the $t$ test for continuous variables and the $x 2$ test for categorical variables

${ }^{\mathrm{b}}$ Adjusted by age, Child, MELD, presence of HCC and pre-transplantation hemoglobin 
dilutional anemias $[58,60]$. In the present study we did not find any difference in the incidence of thrombotic complications between the phases studied. A recent study showed that PCC may be more effective than FFP to restore thrombin generation in patients undergoing liver transplantation, and that the required dose is less than the dose used for warfarin reversal [61].

Transfusional triggers associated to VET are not well stablished in the scientific literature. Most of the studies that propose an algorithm based on VET use the evaluation of the amplitude in the EXTEM at the tenth minute $\left(\mathrm{A} 10_{\mathrm{EX}}\right)[36,41,57,62]$. The use of $\mathrm{A} 5_{\mathrm{EX}}$ has already been shown as an effective parameter to detect thrombocytopenia and hypofibrinogenemia in patients undergoing liver transplantation [63].

Hyperfibrinolysis is an important cause of bleeding in patients undergoing liver transplantation [64]. Thus, antifibrinolytic drugs are used to reduce blood loss and transfusion of blood components, reducing costs and complications, and the decision to use this resource should be individualized because of the theoretical risk of thromboembolic events, which is still a matter of debate $[65,66]$. The high incidence of fibrinolysis disturbances found in patients undergoing liver transplantation has made the use of antifibrinolytics desirable in the past, with the exclusion of patients who are more prone to thrombotic events, such as patients with inflammatory diseases of the biliary tract, previous history of thrombotic events and patients with cellular hepatocarcinoma or other types of cancer. However, it has been shown that in most situations where fibrinolysis is present in a liver transplant, it is transient and do not need intervention [67]. The introduction of ROTEM as a tool for the evaluation of coagulation allows the identification of patients who are prone to fibrinolysis and patients who are bleeding because of fibrinolysis, and these are the patients who benefit from the use of antifibrinolytics $[68,69]$. Such targeted treatment may be a possible explanation of the reduction in the use of antifibrinolytics observed in our study. Finally, it is important to state that ROTEM can point to the possibility of hyperfibrinolysis if there is an increased clot lysis, but the diagnosis is possible after another specific test (APTEM) is performed, showing an improvement with the use of antifibrinolytic drugs, and this diagnosis takes time [70].

Our study has some limitations, including the small sample size, single center design, and the use of non-concurrent controls. We did not collect and include in our models patients' characteristics regarding ICU admission and the use of preoperative mechanical ventilation, dialysis, and vasopressors. Furthermore, the intervention and control periods occurred during different periods, without blinding in the prospective group and it is not possible to control practice parameters that may have changed, for example if the surgeons became more experienced, or if the anesthesiologist had more attention to limiting blood products or a different anesthesia practice pattern. Besides, we do not have data on quantitative blood loss, there was not a standard procedure to guide transfusions in the control group and some patients in the intervention group needed cryoprecipitate after the use of FC, possibly due to lack of other coagulation factors not available in the synthetic concentrate (factors VIII, XIII or von-Willebrand).

In conclusion, our data show that the introduction of a VET-guided transfusion algorithm with the use of synthetic factor concentrates reduces the transfusion rates of allogenic blood in patients submitted to liver transplantation without increasing the risk of thrombosis. Further studies are necessary to identify whether there is an impact on the morbidity and mortality of these patients.

\section{Additional files}

Additional file 1: Association between viscoelastic tests-guided therapy with synthetic factor concentrates and allogenic blood transfusion in liver transplantation: a before-after study - Online Supplement. These Table S1, S2, S3, S4 contain data analysis related to transfusion of blood products and clinical outcomes in both the unmatched and matched cohorts. (DOCX $32 \mathrm{~kb})$

\section{Abbreviations}

APTT: Activated Partial Thromboplastin Time; BIS: Bi-spectral Index; Cl: Confidence Interval; CVP: Central Venous Pressure; FFP: fresh frozen plasma; HCC: Hepatocellular Carcinoma; ICU: Intensive Care Unit; INR: International Normalized Ratio; MAP: Mean Arterial Pressure; MELD: Model of End-stage Liver Disease; OR: Odds Ratio; PPC: Prothrombin Complex Concentrate; RBC: red blood cells; ROTEM: Rotational thromboelastometry; TEG: Thromboelastography; VET: Viscoelastic tests

\section{Acknowledgements}

Presented at ASA 2017 meeting on Oct 22th, 2017, in Boston - MA - USA. Name: Use of synthetic hemoderivatives combined with a

thromboelastometry-guided transfusional algorithm may affect blood product requirements in Liver Transplantation.

\section{Funding}

Support was provided solely from institutional and/or departmental sources.

Availability of data and materials

All data and material are kept by the corresponding author and are available in paper for any further question.

\section{Authors' contributions}

RPCZ: made substantial contributions to conception and design, acquisition, analysis and interpretation of data; was involved in drafting the manuscript; gave final approval of the version to be published and agreed to be accountable for all aspects of the work in ensuring that questions related to the accuracy or integrity of any part of the work are appropriately investigated and resolved. TCA: made substantial contributions to acquisition of data, was involved in drafting the manuscript. VNFQ: made substantial contributions to acquisition of data, was involved in drafting the manuscript. JDOL: made substantial contributions to acquisition of data, was involved in drafting the manuscript. LGVC: was involved in revising the manuscript critically for important intellectual content, made substantial contributions to analysis and interpretation of data. FT: made substantial contributions to conception and design, was involved in revising the manuscript critically for 
important intellectual content. NPJ: was involved in revising the manuscript critically for important intellectual content, made substantial contributions to conception and design, analysis and interpretation of data. ASN: made substantial contributions to conception and design, analysis and interpretation of data; was involved in revising the manuscript critically for important intellectual content; gave final approval of the version to be published; agreed to be accountable for all aspects of the work in ensuring that questions related to the accuracy or integrity of any part of the work are appropriately investigated and resolved. All authors read and approved the final manuscript.

\section{Ethics approval and consent to participate}

The protocol was approved by the local ethics committee of Hospital Israelita Albert Einstein (Comitê de Ética do Hospital Israelita Albert Einstein, São Paulo, Brazil). Written consent was applied to patients in the prospective group (intervention group), and was waived in the restrospective group (control group).

\section{Consent for publication}

\section{Not Applicable.}

\section{Competing interests}

The author Ary Serpa Neto is a member of the editorial board (Associate Editor) of this journal.

The other authors declare no competing interests.

\section{Publisher's Note}

Springer Nature remains neutral with regard to jurisdictional claims in published maps and institutional affiliations.

\section{Author details}

'Department of Transplant Anesthesia, Hospital Israelita Albert Einstein, Rua Galeno de Almeida 107 ap 172-A, Pinheiros, SP 05410-030, Brazil. ${ }^{2}$ Resident of the Anesthesiology Program, Hospital Israelita Albert Einstein, São Paulo, Brazil. ${ }^{3}$ Department of Critical Care Medicine, Hospital Israelita Albert Einstein São Paulo, Brazil. ${ }^{4}$ Department of Intensive Care, Academic Medical Center, University of Amsterdam, Amsterdam, The Netherlands.

\section{Received: 3 September 2018 Accepted: 3 December 2018}

\section{Published online: 22 December 2018}

\section{References}

1. Rana A, Petrowsky H, Hong JC, Agopian VG, Kaldas FM, Farmer D, Yersiz H, Hiatt JR, Busuttil RW. Blood transfusion requirement during liver transplantation is an important risk factor for mortality. J Am Coll Surg. 2013:216(5):902-7.

2. Sahu S, Hemlata VA. Adverse events related to blood transfusion. Indian J Anaesth. 2014:58(5):543-51.

3. Mannucci PM, Tripodi A. Liver disease, coagulopathies and transfusion therapy. Blood Transfus. 2013;11(1):32-6.

4. Maxwell MJ, Wilson MJA. Complications of blood transfusion. Contin Educ Anaesth Crit Care Pain. 2006;6:225-9.

5. Romero FA, Razonable RR. Infections in liver transplant recipients. World J Hepatol. 2011;3(4):83-92.

6. Massicotte L, Sassine MP, Lenis S, Roy A. Transfusion predictors in liver transplant. Anesth Analg. 2004;98(5):1245-51

7. Yuasa T, Niwa N, Kimura S, Tsuji H, Yurugi K, Egawa H, Tanaka K, Asano H, Maekawa T. Intraoperative blood loss during liver transplantation: an analysis of 635 recipients at a single center. Transfusion. 2005:45(6):879-84

8. Warner P, Fusai G, Glantzounis GK, Sabin CA, Rolando N, Patch D, Sharma D, Davidson BR, Rolles K, Burroughs AK. Risk factors associated with early hepatic artery thrombosis after orthotopic liver transplantation - univariable and multivariable analysis. Transpl Int. 2011;24(4):401-8.

9. de Boer MT, Christensen MC, Asmussen M, van der Hilst CS, Hendriks HG, Slooff MJ, Porte RJ. The impact of intraoperative transfusion of platelets and red blood cells on survival after liver transplantation. Anesth Analg. 2008; 106(1):32-44.

10. Liu S, Fan J, Wang X, Gong Z, Wang S, Huang L, Xing T, Li T, Peng Z, Sun X. Intraoperative cryoprecipitate transfusion and its association with the incidence of biliary complications after liver transplantation--a retrospective cohort study. PLoS One. 2013;8(5):e60727.
11. Ramos E, Dalmau A, Sabate A, Lama C, Llado L, Figueras J, Jaurrieta E. Intraoperative red blood cell transfusion in liver transplantation. Influence on patient outcome, prediction of requirements, and measures to reduce them. Liver Transpl. 2003:9(12):1320-7.

12. Cacciarelli TV, Keeffe EB, Moore DH, Burns W, Busque S, Concepcion W, So SK, Esquivel CO. Effect of intraoperative blood transfusion on patient outcome in hepatic transplantation. Arch Surg. 1999;134(1):25-9.

13. Goodnough LT, Brecher ME, Kanter H, AuBuchon JP. Transfusion medicine. First of two part - blood transfusion. N Engl J Med. 1999;340(6):438-47.

14. Goodnough LT, Brecher ME, Kanter H, AuBuchon JP. Transfusion medicine. Second of two parts - blood conservation. N Engl J Med. 1999:340(6):525-33.

15. Spahn DR, Casutt M. Eliminating blood transfusions. New aspects and perspectives. Anesthesiology. 2000;93(1):242-55.

16. Saner FH, Gieseler RK, Akız H, Canbay A, Gorlinger K. Delicate balance of bleeding and thrombosis in end-stage liver disease and liver transplantation. Digestion. 2013;88(3):135-44.

17. Tripodi A, Salerno F, Chantarangkul V, Clerice M, Cazzaniga M, Primignani M, Mannucci PM. Evidence of normal thrombin generation in cirrhosis despite abnormal conventional coagulation tests. Hepatology. 2005;41(3):553-8.

18. Lisman T, Bakhtiari K, Pereboom IT, Hendriks HG, Meijers JC, Porte RJ. Normal to increased thrombin generation in patients undergoing liver transplantation despite prolonged conventional coagulation tests. J Hepatol. 2010;52(3):355-61.

19. Tripodi A, Primignani M, Chantarangkul V, Clerici M, Dell'Era A, Fabirs F, Salerno F, Mannucci PM. Thrombin generation in patients with cirrhosis: the role of platelets. Hepatology. 2006;44(2):440-5.

20. Lisman T, Stravitz RT. Rebalanced hemostasis in patients with acute liver failure Semin Thromb Hemost. 2015:41(5):468-73.

21. Tripodi A, Primignani M, Mannucci PM, Caldwell SH. Changing concepts of cirrhotic coagulopathy. Am J Gastroenterol. 2017;112(2):274-81.

22. Hartmann M, Szalai C, Saner FH. Hemostasis in liver transplantation: pathophysiology, monitoring, and treatment. World J Gastroenterol. 2016 22(4):1541-50

23. Kang YG, Martin DJ, Marquez J, Lewis JH, Bontempo FA, Shaw BW Jr, Starlz TE, Winter PM. Intraoperative changes in blood coagulation and thrombelastographic monitoring in liver transplantation. Anesth Analg. 1985;64(9):888-96.

24. Hartert H. Blutgerinnungstudien mit der Thrombelastographie, einem neuen Untersuchungs verfahren. Klin Wochenschr. 1948;26(37-38):557-83.

25. Luddington RJ. Thrombelastography/thromboelastometry. Clin Lab Haematol. 2005;27(2):81-90.

26. Hett DA, Walker D, Pilkington SN, Smith DC. Sonoclot analysis. Br J Anaesth. 1995;75(6):771-6.

27. Weber CF, Görlinger K, Meininger D, Hermann E, Bingold T, Moritz A, Cohn LH, Zacharowski K. Point-of-care testing: a prospective, randomized clinical trial of efficacy in coagulopathic cardiac surgery patients. Anesthesiology. 2012:117(3):531-47.

28. Davenport R, Khan S. Management of major trauma haemorrhage: treatment priorities and controversies. Br J Haematol. 2011;155(5):537-48.

29. Wang SC, Shieh JF, Chang KY, Chu YC, Liu CS, Loong CC, Chan KH, Mandell S, Tsou MY. Thromboelastography-guided transfusion decreases intraoperative blood transfusion during orthotopic liver transplantation: randomized clinical trial. Transplant Proc. 2010:42(7):2590-3.

30. Clevenger B, Mallett SV. Transfusion and coagulation management in liver transplantation. World J Gastroenterol. 2014;20(20):6146-58

31. Gurusamy KS, Pissanou T, Pikhart H, Vaughan J, Burroughs AK, Davidson BR. Methods to decrease blood loss and transfusion requirements for liver transplantation. Cochrane Database Syst Rev. 2011;12:CD009052.

32. Freitas AC, Itikawa WM, Kurogi AS, Stadnik LG, Parolin MB, Coelho JC. The impact of the model for end-stage liver disease (MELD) on liver transplantation in one center in Brazil. Arq Gastroenterol. 2010;47(3):233-7.

33. Varotti G, Santori G, Andorno E, Morelli N, Ertreo M, Strada P, Porcile E, Casaccia M, Centanaro M, Valente U. Impact of model for end-stage liver disease score on transfusion rates in liver transplantation. Transplant Proc. 2013;45(7):2684-8

34. Görlinger K, Dirkmann D, Hanke AA, Kamler M, Kottenberg E, Thielmann M, Jakob H, Peters J. First-line therapy with coagulation factor concentrates combined with point-of-care coagulation testing is associated with decreased allogeneic blood transfusion in cardiovascula surgery: a retrospective, single-center cohort study. Anesthesiology. 2011;115(6):1179-91. 
35. Agarwal A, Sharma N, Vij V. Point-of-care coagulation monitoring during liver transplantation. Trends in Anaesthesia and Critical Care. 2013;3:42-8.

36. Blasi A, Beltran J, Pereira A, Martinez-Palli G, Torrents A, Balust J, Zavala E, Taura P, Garcia-Valdecasas JC. An assessment of thromboelastometry to monitor blood coagulation and guide transfusion support in liver transplantation. Transfusion. 2012;52(9):1989-98.

37. McCluskey SA, Karkouti K, Wijeysundera DN, Kakizawa K, Ghannam M, Hamdy A, Grant D, Levy G. Derivation of a risk index for the prediction of massive blood transfusion in liver transplantation. Liver Transpl. 2006;12(11): 1584-93.

38. Ganter MT, Hofer CK. Coagulation monitoring: current techniques and clinical use of viscoelastic point-of-care coagulation devices. Anesth Analg. 2008;106(5):1366-75

39. Hanke AA, Herold U, Dirkmann D, Tsagakis K, Jakob H, Görlinger K. Thromboelastometry based early goal-directed coagulation management reduces blood transfusion requirements, adverse events, and costs in acute type a aortic dissection: a pilot study. Transfus Med Hemother. 2012;39(2): $121-8$.

40. Lier H, Bottiger BW, Hinkelbein J, Krep H, Bernhard M. Coagulation management in multiple trauma: a systematic review. Intensive Care Med. 2011;37(4):572-82

41. Gorlinger K, Fries D, Dirkmann D, Weber C, Hanke A, Schochl H. Reduction of fresh frozen plasma requirements by perioperative point-of-care coagulation management with early calculated goal- directed therapy. Transfus Med Hemother. 2012;39(2):104-13.

42. Gorlinger K. Coagulation management during liver transplantation. Hamostaseologie. 2006;26(3 suppl 1):S64-76.

43. Kirchner C, Dirkmann D, Treckmann JW, Paul A, Hartmann M, Saner $\mathrm{FH}$, Gorlinger K. Coagulation management with factor concentrates in liver transplantation: a single-center experience. Transfusion. 2014; 54(10Pt2):2760-8.

44. Bell SF, Rayment R, Collins PW, Collis RE. The use of fibrinogen concentrate to correct hypofibrinogenaemia rapidly during obstetric haemorrhage. Int J Obstet Anesth. 2010;19(2):218-23.

45. Karlsson M, Ternstrom L, Hyllner M, Baghaei F, Flinck A, Skrtic S, Jeppsson A. Prophylactic fibrinogen infusion reduces bleeding after coronary artery bypass surgery. A prospective randomised pilot study. Thromb Haemost. 2009;102(1):137-44.

46. Schochl H, Nienaber U, Hofer G, Voelckel W, Jambor C, Scharbert G, KozekLangenecker S, Solomon C. Goal-directed coagulation management of major trauma patients using thromboelastometry (ROTEM)-guided administration of fibrinogen concentrate and prothrombin complex concentrate. Crit Care. 2010;14(2):R55.

47. Sorensen B, Bevan D. A critical evaluation of cryoprecipitate for replacement of fibrinogen. Br J Haematol. 2010;149(6):834-43.

48. Chowdhury P, Saayman AG, Paulus U, Findlay GP, Collins PW. Efficacy of standard dose and $30 \mathrm{ml} / \mathrm{kg}$ fresh frozen plasma in correcting laboratory parameters of haemostasis in critically ill patients. Br J Haematol. 2004; 125(1):9-73.

49. Rahe-Meyer N, Sorensen B. Fibrinogen concentrate for management of bleeding. J Thromb Haemost. 2011;9(1):1-5.

50. Palomo Sanchez JC, Jiménez C, Moreno Gonzalez E, Garcia I, Palma F, Loinaz C, Gonzalez Ghamorro A. Effects of intraoperative blood transfusion on postoperative complications and survival after orthotopic liver transplantation. Hepatogastroenterology. 1998;45(22):1026-33.

51. Janatpour K, Holland PV. Noninfectious serious hazards of transfusion. Curr Hematol Rep. 2002;1(2):149-55.

52. Nascimento B, Goodnough LT, Levy JH. Cryoprecipitate therapy. Br J Anaesth. 2014;113(6):922-34

53. Novakovic Anucin S, Kosanovic D, Gnip S, Canak V, Cabarkapa V, Mitic G. Comparison of standard coagulation tests and rotational thromboelastometryfor hemostatic system monitoring during orthotopic liver transplantation - results from a pilot study. Med Pregl. 2015;68(9-10):301-7.

54. Sabate A, Dalmau A. Fibrinogen: a clinical update on liver transplantation. Transplant Proc. 2015;47(10):2925-8.

55. Coakley M, Reddy K, Mackie I, Mallett S. Transfusion triggers in orthotopic liver transplantation: a comparison of the thromboelastometry analyzer, the thromboelastogram, and conventional coagulation tests. J Cardiothorac Vasc Anesth. 2006;20(4):548-53.

56. Pereboom IT, de Boer MT, Haagsma EB, Hendriks HG, Lisman T, Porte RJ. Platelet transfusion during liver transplantation is associated with increased postoperative mortality due to acute lung injury. Anesth Analg. 2009;108(4): 1083-91.

57. Roullet S, Pillot J, Freyburger G, Biais M, Quinart A, Rault A, Revel P, Sztark F. Rotation thromboelastometry detects thrombocytopenia and hypofibrinogenaemia during orthotopic liver transplantation. Br J Anaesth. 2010:104(4):422-8.

58. Sarode R, Milling TJ Jr, Refaai MA, Mangione A, Scheneider A, Durn BL, Goldstein JN. Efficacy and safety of a 4-factor prothrombin complex concentrate in patients on vitamin $\mathrm{K}$ antagonists presenting with major bleeding: a randomized, plasma-controlled, phase Illb study. Circulation. 2013;128(11):1234-43.

59. Tanaka KA, Mazzeffi M, Durila M. Role of prothrombin complex concentrate in perioperative coagulation therapy. J Intensive Care. 2014;2(1):60.

60. Hanke AA, Joch C, Gorlinger K. Long-term safety and efficacy of a pasteurized nanofiltrated prothrombin complex concentrate (Beriplex P/N): a pharmacovigilance study. Br J Anaesth. 2013;110(5):764-72.

61. Abuelkasem E, Hasan S, Mazzeffi MA, Planinsic RM, Sakai T, Tanaka KA. Reduced requirement for prothrombin complex concentrate for the restoration of thrombin generation in plasma from liver transplant recipients. Anesth Analg. 2017;125(2):609-15.

62. Roullet S, Freyburguer G, Cruc M, Quinart A, Stecken L, Audy M, Chiche L, Sztark F. Management of bleeding and transfusion during liver transplantation before and after the introduction of a rotational thromboelastometry-based algorithm. Liver Transpl. 2015;21(2):169-79.

63. Song JG, Jeong SM, Jun IG, Lee HM, Hwang GS. Five-minute parameter of thromboelastometry is sufficient to detect thrombocytopenia and hypofibrinogenaemia in patients undergoing liver transplantation. $\mathrm{Br}$ J Anaesth. 2014;112(2):290-7.

64. Roullet S, Freyburger G, Labrouche S, Morisse E, Stecken L, Quinart A, Laurent C, Sztark F. Hyperfibrinolysis during liver transplantation is associated with bleeding. Thromb Haemost. 2015;113(5):1145-8.

65. Xia WW, Steadman RH. Antifibrinolytics in orthotopic liver transplantation: current status and controversies. Liver Transpl. 2005:11(1):10-8.

66. Makwana J, Paranjape S, Goswami J. Antifibrinolytics in liver surgery. Indian J Anaesth. 2010;54(6):489-95.

67. Poon KS, Chen CC, Thorat A, Chiang YY, Jeng LB, Yang HR, Chen TH, Yeh CC, Chen KB. Fibrinolysis after reperfusion of liver graft. Acta Anaesthesiol Taiwanica. 2015;53(1):41-3.

68. Bolliger D, Seeberger MD, Tanaka KA. Principles and practice of thromboelastography in clinical coagulation management and transfusion practice. Transfus Med Rev. 2012;26(1):1-13.

69. Blasi A. Coagulopathy in liver disease. Lack of an assessment tool. World J Gastroenterol. 2015;21(35):10062-71.

70. Ilich A, Bokarev I, Key NS. Global assays of fibrinolysis. Int J Lab Hematol. 2017;39(5):441-7.
Ready to submit your research? Choose BMC and benefit from:
- fast, convenient online submission
- thorough peer review by experienced researchers in your field
- rapid publication on acceptance
- support for research data, including large and complex data types
- gold Open Access which fosters wider collaboration and increased citations
- maximum visibility for your research: over $100 \mathrm{M}$ website views per year
At BMC, research is always in progress.
Learn more biomedcentral.com/submission 